\title{
Desarrollo del turismo rural integrado desde la perspectiva de los residentes: modelo propuesto
}

\author{
Mercedes Marzo-Navarro* \\ Universidad de Zaragoza (España)
}

\begin{abstract}
Resumen: Se propone un modelo holístico que refleja el proceso de desarrollo de un Turismo Rural Integrado (TRI). Dicho modelo recoge las principales variables implicadas en el desarrollo de este tipo de turismo así como las relaciones existentes entre ellas. El modelo se valida teniendo en cuenta la información proporcionada por los residentes de una zona implicada en un proyecto de desarrollo turístico rural. La zona es la provincia de Entre Ríos (Argentina), inmersa en el desarrollo del destino turístico "Tierra de Palmares". Los residentes constituyen uno de los principales stakeholders para que el TRI pueda desarrollarse con éxito. La metodología aplicada es la proporcionada por los modelos de ecuaciones estructurales con variables latentes. Los resultados muestran que los residentes perciben la existencia de las variables clave para alcanzar el desarrollo del TRI. Se comprueba que la existencia de colaboración entre los agentes implicados constituye el punto de partida para el desarrollo turístico, ya que afecta al carácter arraigado, endógeno y complementario de las actividades turísticas desarrolladas, así como al empoderamiento de los residentes. Además, se alcanzan los objetivos de sostenibilidad económica, sociocultural y medioambiental. Dichas sostenibilidades se ven afectadas por el empoderamiento de los residentes en la zona.
\end{abstract}

Palabras clave: Turismo rural integrado, Residentes, Redes, Arraigo, Endogeneidad, Complementariedad, Empoderamiento, Escala, Sostenibilidad

\section{Development of integrated rural tourism from the residents' perspective: proposed model}

Abstract: A holistic model that reflects the development process of Integrated Rural Tourism (IRT) is proposed. The model includes the main variables involved in the development of this type of tourism, as well as the relationships that exist between those variables. The model is validated considering the information provided by the residents of a rural area involved a tourism development project. The area is the province of Entre Ríos (Argentina), immersed in the development of the tourist destination "Tierra de Palmares".The residents constitute one of the main stakeholders so that IRT can be successfully developed. The methodology applied is that provided by the structural equation models with latent variables. The results obtained show that residents perceive the existence of the key variables to successfully develop IRT. Residents' perceptions show that the existence of collaboration between the stakeholders has a positive relationship with the other aspects of integrated tourism, given that it affects the embedded, endogenous, and complementary nature of the developed tourism activities, as well as the empowerment of the residents. Moreover, the three dimensions of sustainability are reached, given that the existence of economic, socio-cultural, and environmental sustainability is perceived. These sustainability dimensions are affected by the empowerment of the residents of an area.

Key words: Integrated Rural Tourism, Residents, Networks, Embeddedness, Endogeneity, Complementarity, Empowerment, Scale, Sustainability.

\section{Introducción}

El turismo es uno de los principales sectores de la economía mundial. Implica importantes transferencias de riqueza, y favorece el desarrollo y el crecimiento económico de las zonas de destino. En 2015, la contribución del turismo al PIB y al empleo mundial creció un $3,1 \%$ y un $2,6 \%$ respectivamente, lo que demuestra que, a pesar de la crisis, el turismo es un motor clave para la economía, manteniéndose las

Titular de Universidad. Departamento de Dirección de Marketing e Investigación de Mercados; E-mail: mmarzo@ unizar.es 
expectativas para los próximos años (World Travel \& Tourism Council, 2016). Este papel del turismo ha sido adoptado por numerosos organismos oficiales, ya que es considerado como una herramienta clave para el desarrollo de determinadas regiones (Barke, 2004; Panyik, Costa \& Rátz, 2011; Ghaderi \& Henderson, 2012; Pérez \& Zizumbo, 2014). A pesar de estos datos favorables, se debe tener en cuenta que la magnitud y el crecimiento del turismo ejercen una gran presión en el medioambiente y en los recursos socioculturales del destino. Esta presión debe tenerse en cuenta para poder realizar una gestión eficiente de los recursos (Rojas, 2009; Deery, Jagb \& Fredline, 2012). Además, las tendencias globales en el sector muestran que los turistas buscan experiencias vinculadas a la sostenibilidad (Alonso \& Celemín, 2016), por lo que dicha sostenibilidad debe constituir un objetivo estratégico para cualquier destino (Simao \& Partidario, 2012).

Las características del entorno rural convierten al turismo en una herramienta de reactivación socioeconómica (Garín, 2015). El turista actual se caracteriza por su creciente capacidad de elección. Es un consumidor exigente, y su tiempo de ocio es esencial para su autorrealización personal y social. Por tanto, el turismo que realiza no es un simple desplazamiento a un lugar donde hay algo, sino una actividad más compleja y participativa. Se trata de ir a un lugar para hacer algo, para experimentar vivencias (Avila \& Barrado, 2005). Entre estas vivencias destaca la vuelta al entorno rural, a experimentar un estilo de vida diferente, asociado a la cercanía a la naturaleza y a un entorno saludable (Pitarch, Buciega \& Esparcia, 2004). Así, determinadas zonas rurales son percibidas como poseedoras de un elevado potencial turístico al existir recursos como paisajes naturales, culturas, tradiciones, posibilidad de realizar actividades al aire libre o gastronomía (Navarro, 2015), cuya valorización turística permite la creación de atractivos turísticos. Las industrias tradicionales de estas zonas pueden complementar sus actividades con el turismo, formando un producto turístico que responda a la demanda de nuevas experiencias (Kastenholz, Carneiro, Marques \& Lima, 2012). De esta manera, el turismo se convierte en una alternativa para la diversificación y la reconversión de áreas rurales (Galloway, Sanders \& Deakins, 2011; Zou, Huang \& Ding, 2012). Pero el desarrollo turístico rural no sólo genera beneficios. En él participan una gran diversidad de actores, instalaciones y recursos, entre los que existen múltiples relaciones, que deben ser considerados y gestionados correctamente para no obstaculizar el camino hacia un desarrollo sostenible (Barcus, 2013). La sostenibilidad resulta ser una variable clave para lograr la competitividad de un destino (Wordl Economic Forum, 2013), aunque conseguirla no sea tarea fácil. En general, se habla de turismo sostenible cuando se aplican los principios de desarrollo sostenible en sus dimensiones económica, medioambiental y social (Park \& Yoon, 2011). Este objetivo cobra especial importancia en el desarrollo de nuevos destinos, cuya capacidad de atracción sólo será lo suficientemente importante cuando integre todas las variables sociales, culturales, geográficas y económicas del ámbito de acogida (Avila \& Barrado, 2005).

Una de las estrategias que permite gestionar esta compleja realidad es el enfoque del Turismo Rural Integrado (TRI), que proporciona un marco de análisis integral y un modelo de desarrollo turístico holístico. El TRI es un turismo que está explícitamente relacionado con las estructuras económicas, sociales, culturales, naturales y humanas del entorno en el que se desarrolla (Barcus, 2013; Garín, 2015). Para poder gestionarlo con éxito es necesaria la implicación de los residentes en la zona (Jurowsky \& Gursoy, 2004; Pérez \& Nadal, 2005; Dyer et al., 2007), por lo que el conocimiento de sus opiniones resulta clave (Vargas, Plaza \& Porras, 2009; Gursoy, Chi \& Dyer, 2010; Almeida et al., 2016).

La literatura especializada muestra distintas conceptualizaciones del TRI así como de las variables implicadas en su desarrollo (Jenkins \& Oliver, 2001; Saxena et al., 2007; Saxena \& Ilbery, 2008; Cawley \& Gillmor, 2008; Sims, 2010; Panyik, Costa \& Rátz, 2011; Barcus, 2013). Sin embargo, no existe un modelo que proponga y valide empíricamente las interrelaciones existentes entre las variables que dan lugar al desarrollo de un TRI exitoso. Así, el principal objetivo de esta investigación pretende subsanar esta carencia, comprobando empíricamente un modelo de desarrollo del TRI.

\section{Turismo Rural Integrado}

La revisión de la literatura muestra que no existe consenso sobre lo que se debe entender por turismo rural y, por tanto, por Turismo Rural Integrado. Parte de esta falta de consenso se debe a la propia definición del concepto de rural. En los últimos años se ha producido una modificación sustancial del concepto "rural" debido a las modificaciones espaciales, funcionales y socioeconómicas experimentadas por este entorno (Sancho \& Reinoso, 2012). Así, la Comisión Europea (1988) establece que el mundo rural abarca aquellas zonas y regiones donde se llevan a cabo actividades diversas e incluiría espacios 
naturales y cultivados, pueblos, villas, ciudades pequeñas y centros regionales, así como zonas rurales industrializadas. Se evoca así a un tejido económico y social que incluye actividades muy diversas (agricultura, artesanía, pequeñas y medianas industrias, comercios y servicios). Por tanto, la ruralidad se caracteriza por la presencia de actividades heterogéneas y diversas, donde se establecen relaciones sociales complejas (Giarracca, 2001). Así, el concepto de rural ha pasado de ser sinónimo de atrasado a ser una ruralidad complementaria a lo urbano, sinónimo de calidad de vida (Sancho \& Reinoso, 2012).

En este contexto y en su noción amplia, el turismo rural se refiere al conjunto de actividades que se desarrollan en el espacio rural, en el cual se engloban los paisajes naturales, montañas, campos, formas de vida, folclore, arquitectura típica, gastronomía, etc. En definitiva, todo aquello que despierta el interés de personas que viven habitualmente en un medio urbano al ser percibido como algo distinto y positivo, y por lo que están dispuestos a trasladarse y a gastar dinero en experimentarlo (Pitarch, Buciega \& Esparcia, 2004). Por su parte, el concepto de integrado se basa en los planteamientos realizados desde el desarrollo rural integrado cuyo objetivo es que la maximización del valor añadido generado se quede en la zona. Es decir, se pretende la "reactivación de zonas desfavorecidas a través de actividades explotadoras de sus recursos con técnicas productivas autóctonas, con financiación basada en el ahorro interior y con trabajadores radicados en la zona" (Muñoz de Escalona, 1994; 19). Así, en sus inicios, el TRI supone un concepto orientado a la planificación, gestión y comercialización del turismo rural, respetando la biodiversidad, la identidad cultural, la mejora de las rentas familiares y del nivel de vida de las comunidades locales (Muñoz de Escalona, 1994).

La revisión de la literatura muestra que, en efecto, las principales definiciones académicas del TRI, reflejadas en el Cuadro 1, se centran en la integración como elemento clave. Así, el TRI se centra en la integración de las variables económicas y sociales en las que se sustenta, siendo su objetivo la consecución de un turismo sostenible. De esta manera, el TRI supone un avance sobre el desarrollo del enfoque del Turismo Sostenible (Sharpley, 2003). En su concepción más sencilla, el turismo sostenible se refiere a una forma de turismo que puede mantener la viabilidad de un área durante un periodo de tiempo indefinido (Butler, 1999). El TRI va más allá, al enfatizar la importancia de la colaboración, la cooperación y la construcción de redes entre los agentes y recursos implicados en el desarrollo turístico que permita alcanzar la sostenibilidad (Barcus, 2013).

\section{Cuadro 1.Definiciones de Turismo Rural Integrado}

\begin{tabular}{ll}
\hline & $\begin{array}{l}\text { Concepto innovador del turismo orientado a la planificación, gestión y } \\
\text { comercialización del turismo rural. Su carácter innovador se debe a las técnicas } \\
\text { de producción de ingeniería turística, a la gestión empresarial de actividades } \\
\text { productivas verticalmente integradas, al desarrollo rural integrado, a la identidad } \\
\text { cultural del espacio en el que se localiza, y a la diversidad biológica del entorno } \\
\text { medioambiental. }\end{array}$ \\
\hline $\begin{array}{l}\text { Jenkins \& Oliver } \\
(2001)\end{array}$ & $\begin{array}{l}\text { Turismo explícitamente relacionado con los recursos económicos, sociales, } \\
\text { culturales, naturales y humanos de las localidades en las que se desarrolla. }\end{array}$ \\
\hline Saxena et al. (2007) & $\begin{array}{l}\text { Forma de entender, crítica y comprensivamente, a los actores, recursos y relaciones } \\
\text { involucrados en la fragmentada industria turística. Conceptualización holística del } \\
\text { turismo, que implica investigar a sus múltiples actores y relaciones }\end{array}$ \\
\hline Saxena \& Ilbery & $\begin{array}{l}\text { Turismo basado en redes sociales que explícitamente conectan a los actores con } \\
\text { el objetivo de promover y mantener los recursos económicos, sociales, culturales, } \\
\text { naturales y humanos en las localidades en la que se desarrolla }\end{array}$ \\
\hline Cawley \& Gillmor & $\begin{array}{l}\text { Turismo relacionado con la conceptualización normativa de sostenibilidad, esto es, } \\
\text { la satisfacción de las necesidades de las generaciones presentes debe realizarse con } \\
\text { métodos y recursos que no comprometan a las generaciones futuras. Se basa en } \\
\text { promover la sostenibilidad medioambiental, económica y sociocultural, empoderar a } \\
\text { las comunidades locales, y contribuir a la sostenibilidad del sistema rural. }\end{array}$ \\
\hline Sims (2008) & $\begin{array}{l}\text { Turismo que pretende mejorar la economía, la cultura y el medio ambiente } \\
\text { local para crear una comunidad local sólida que pueda ser disfrutada tanto por } \\
\text { residentes como por visitantes. }\end{array}$ \\
\hline Barcus (2013) & $\begin{array}{l}\text { Marco detallado para que las comunidades rurales desarrollen las infraestructuras } \\
\text { turísticas, incluyendo un componente de sostenibilidad }\end{array}$ \\
\hline
\end{tabular}

Fuente: Elaboración Propia 
En la práctica, el TRI se refiere a aquel que tiene claras conexiones con los recursos, productos y habitantes locales (Oliver \& Jenkins, 2003; Saxena et al., 2007). Su objetivo es promover la sostenibilidad medioambiental, económica y sociocultural del sistema rural, radicando el poder de decisión y de actuación en los habitantes de la zona (Cawley \& Gilmore, 2008). La integración representa la necesaria creación de relaciones entre los actores y recursos a través de la cooperación y la colaboración (Saxena, 2005). Esta colaboración requiere la puesta en común de los conocimientos, la experiencia, el capital y otros recursos de los distintos stakeholders (Bramwell \& Lane, 2000), siendo indispensable la participación de los stakeholders locales (Ray, 2000). Así, los residentes forman parte del producto turístico, ya que sus actitudes positivas constituyen un prerrequisito para el desarrollo del turismo (Nunkoo \& Gursay, 2011; Lee, 2013; Sinclair, Gursoy \& Vieregge, 2015), afectando a la puesta en práctica de los procesos de planificación de los destinos (Kim, Uysal \& Sirgy, 2013). En definitiva, el TRI es aquel que tiene claras conexiones con los recursos locales, las actividades, los productos locales y que incluye la participación de los residentes en el destino turístico.

La literatura muestra que el TRI se hace visible a través de las dimensiones reflejadas en el Cuadro 2. En este Cuadro se refleja, a modo de resumen, la definición de las dimensiones bajo estudio. La integración de estas dimensiones es la que conduce al desarrollo turístico exitoso.

\section{Cuadro 2. Dimensiones de TRI}

\begin{tabular}{|c|c|c|}
\hline VARIABLES & DEFINICIONES & AUTORES \\
\hline Redes & $\begin{array}{l}\text { Lazos relacionales que se conectan agentes, grupos } \\
\text { e instituciones y que son capaces de unir a las } \\
\text { personas y organizaciones de diferentes ambientes } \\
\text { e intereses para alcanzar los objetivos del turismo }\end{array}$ & $\begin{array}{l}\text { Cawley \& Gillmor (2008); Clark \& Chabrel } \\
\text { (2007); Ilbery et al. (2007); Pavlovich } \\
\text { (2003); Petrou et al. (2007); Saxena \& } \\
\text { Ilbery (2008); Stambolius \& Skayannis } \\
\text { (2003) }\end{array}$ \\
\hline Arraigo & $\begin{array}{l}\text { Relación de los recursos, vínculos y actividades } \\
\text { turísticas con la cultura, tradiciones e identidad } \\
\text { local. }\end{array}$ & $\begin{array}{l}\text { Clark \& Chabrel (2007); Ilbery et al. } \\
\text { (2007); Kalantaridis \& Bifka (2006); Oliver } \\
\text { \& Jenkins (2003); Saxena \& Ilbery (2008); } \\
\text { Saxena et al. (2007) }\end{array}$ \\
\hline $\begin{array}{l}\text { Endogenei- } \\
\text { dad }\end{array}$ & $\begin{array}{l}\text { Uso de recursos locales - naturales, humanos, } \\
\text { socioculturales y económicos- para el desarrollo } \\
\text { del turismo. }\end{array}$ & $\begin{array}{l}\text { Cawley \& Gillmor (2008); Clark \& Chabrel } \\
\text { (2007); Ilbery et al. (2007); Ilbery et al. } \\
\text { (2007); Jenkins (2000); Ray (2000); Saxena } \\
\text { \& Ilbery (2008) }\end{array}$ \\
\hline $\begin{array}{l}\text { Complemen- } \\
\text { tariedad }\end{array}$ & $\begin{array}{l}\text { Desarrollo de actividades turísticas junto con } \\
\text { actividades productivas tradicionales de la zona y } \\
\text { uso compartido de recursos por residentes y turistas. }\end{array}$ & $\begin{array}{l}\text { Clark \& Chabrel (2007); Ilbery et al. } \\
\text { (2007); Jamal \& Kim (2005); Petrou et } \\
\text { al. (2007); Saxena \& Ilbery (2008) }\end{array}$ \\
\hline $\begin{array}{l}\text { Empodera- } \\
\text { miento }\end{array}$ & $\begin{array}{l}\text { Fortalecimientos de la confianza y autoestima de } \\
\text { los individuos, consideración de los intereses de } \\
\text { todos los actores de la comunidad y fortalecimiento } \\
\text { de sus capacidades para influenciar y participar en } \\
\text { la administración, supervisión y toma de decisiones } \\
\text { turísticas. }\end{array}$ & $\begin{array}{l}\text { Bandura (1977); Clark \& Chabrel (2007); } \\
\text { Ilbery et al. (2007); Oliver\& Jenkins (2003); } \\
\text { Oxaal \& Baden (1997); Ruiz \&Hernandez } \\
\text { (2010); Saxena \& Ilbery (2008) }\end{array}$ \\
\hline Escala & $\begin{array}{l}\text { Extensión del turismo en términos del tamaño de sus } \\
\text { recursos y de su distribución espacial y temporal en } \\
\text { relación a las infraestructuras (físicas y naturales) } \\
\text { existentes en el área. }\end{array}$ & $\begin{array}{l}\text { Clark \& Chabrel (2007); Ilbery et al. } \\
\text { (2007); Jenkins \& Oliver (2001); Oliver } \\
\text { \& Jenkins (2003) }\end{array}$ \\
\hline $\begin{array}{l}\text { Sosteni- } \\
\text { bilidad } \\
\text { Económica }\end{array}$ & $\begin{array}{l}\text { Referida a los efectos económicos que provoca el } \\
\text { desarrollo del turismo. }\end{array}$ & $\begin{array}{l}\text { Anderek \& Vogt (2000); Byrd et al. (2009); } \\
\text { Clark \& Chabrel (2007); Tsaur et al. (2006) }\end{array}$ \\
\hline $\begin{array}{l}\text { Sostenibili- } \\
\text { dad Sociocul- } \\
\text { tural }\end{array}$ & $\begin{array}{l}\text { Referida a los efectos socioculturales que provoca } \\
\text { el desarrollo del turismo. }\end{array}$ & $\begin{array}{l}\text { Anderek \& Vogt (2000); Byrd et al. (2009); } \\
\text { Clark \& Chabrel (2007); Ilbery et a.l } \\
\text { (2007); Tsaur et al (2006) }\end{array}$ \\
\hline $\begin{array}{l}\text { Sostenibi- } \\
\text { lidad Me- } \\
\text { dioambiental }\end{array}$ & $\begin{array}{l}\text { Referida a los efectos ambientales que provoca el } \\
\text { desarrollo del turismo. }\end{array}$ & $\begin{array}{l}\text { Anderek \& Vogt (2000); Byrd et al. (2009); } \\
\text { Clark \& Chabrel (2007); Ilbery et al. } \\
\text { (2007); Tsaur et al. (2006) }\end{array}$ \\
\hline
\end{tabular}

Fuente: Elaboración Propia 
El concepto de Redes se aborda desde su perspectiva amplia, refiriéndose a las relaciones a través de las cuales los agentes pretenden alcanzar sus objetivos (Pavlovich, 2003; Saxena \& Ilbery, 2008). En las zonas rurales es importante ofertar un producto turístico que atraiga y retenga a los turistas durante varios días. Esto es difícil, ya que las organizaciones existentes suelen ser pequeñas organizaciones familiares con capacidades limitadas, esto es, con escaso capital económico y personal. Por tanto, la existencia de relaciones de colaboración y cooperación permite a estos agentes acceder a información, compartir recursos, desarrollar una visión colectiva, difundir ideas, y movilizar recursos para atraer visitantes. Además, pueden generar oportunidades de nuevas estructuras institucionales y actividades empresariales (Kneafsey, 2001). De esta manera, se pueden equilibrar los intereses de los distintos stakeholders, estimulando las ventajas competitivas de los destinos rurales. Para que el desarrollo sostenible ocurra de manera competitiva, los recursos de la región deben ser integrados en un producto turístico rural local, complementario con los recursos y las actividades locales (Petrou et al., 2007). Así, el desarrollo de redes, con independencia de su tipología, genera una serie de beneficios entre los que destacan: arraigan a las empresas relacionadas con el turismo en el contexto local; median y guían en los compromisos y en las decisiones de inversión necesarias para desarrollar formas de turismo sostenibles y complementarias; facilitan el acceso a los recursos existentes; y asisten a la integración de las empresas por medio de mecanismos de coordinación (Oliver \& Jenkins, 2003; Petrou et al., 2007). Además, las redes sociales inculcan principios y normas culturales (Granovetter, 1985), fortaleciendo los valores compartidos y reafirmando la identidad local. Esto permite el empoderamiento de los individuos de la comunidad, al formar parte del producto turístico ofertado (Saxena \& Ilbery, 2008). Por tanto, se establece que,

- Hipótesis 1: La existencia de redes está positivamente relacionada con el arraigo de los recursos, productos y experiencia turística en el entorno en el que se llevan a cabo.

- Hipótesis 2: La existencia de redes está positivamente relacionada con el uso endógeno de recursos.

- Hipótesis 3: La existencia de redes está positivamente relacionada con la complementariedad de recursos y actividades.

- Hipótesis 4: La existencia de redes está positivamente relacionada con el empoderamiento de la comunidad.

Para mantener la conexión con los recursos de la zona, el turismo debe enfatizar el contexto territorial en el que se va a llevar a cabo. Las relaciones y enraizamiento de las actividades y recursos turísticos con el medio local implican un mayor control de estas actividades y recursos por parte de la comunidad local. Por tanto, se puede establecerse la existencia de una relación entre el arraigo y el empoderamiento de la comunidad, ya que un mayor control local sobre el turismo provocará una mayor focalización del turismo en alcanzar las prioridades locales (Clark \& Chabrel, 2007). Así,

Hipótesis 5: La existencia de actividades, recursos y vínculos turísticos arraigados afectan positivamente al nivel de empoderamiento de la comunidad.

Por otra parte, el mantenimiento de las tradiciones y culturas locales ejerce un efecto positivo en el desarrollo sostenible (Jenkins, 2000), concretamente en su vertiente sociocultural. Socialmente, el arraigo cultural está basado en el concepto de patrimonio como una construcción social, cuyo carácter simbólico le proporciona la capacidad para representar simbólicamente una identidad. Así, agrupa a un conjunto de elementos dentro del cual se constituyen muchos referentes simbólicos patrimoniales derivados de la naturaleza, de la historia y de la inspiración creativa (Prats, 1997). Esta identidad es la que genera el sentido de pertenencia a un grupo; políticamente, la cultura puede ser una estimulante fuente de cohesión y de confianza a largo plazo por lo que las redes involucradas son sostenibles a través del tiempo; y económicamente, los activos culturales son explotables a través de productos diferenciados. La toma de conciencia por parte de los residentes del valor que otorgan otros individuos a estos elementos hace que éstos puedan ser importantes factores de desarrollo, orientando a las regiones a realizar inversiones a largo plazo y a forjar relaciones económica con el mundo externo (Bassand, 1993). Por tanto,

Hipótesis 6: La existencia de actividades, recursos y vínculos turísticos arraigados afectan positivamente a la sostenibilidad sociocultural.

El desarrollo endógeno del turismo implica la existencia de una estructura capaz de retener el máximo de beneficios en la zona, usando y agregando valor a los recursos locales, y centrándose 
en los requerimientos, capacidades y valores de los actores locales (Ray, 2000). Las estrategias endógenas se centran en aspectos económicos, medioambientales y culturales distintivos del entorno. El desarrollo de productos a partir de esos recursos involucra una gran participación local, lo que puede generar un incremento de conciencia de su identidad local (Jenkins \& Oliver, 2001; Ray, 2000). Así, se promueve la participación local en la toma de decisiones sobre el uso de los recursos y permite a los actores locales adaptar las oportunidades externas a sus propias necesidades (Long \& Van der Ploeg, 1994; Ray, 2000). Así,

Hipótesis 7: El uso endógeno de los recursos para el desarrollo turístico está positivamente relacionado con el empoderamiento de la comunidad local.

Este desarrollo endógeno retiene los beneficios en las localidades en las que se produce (Jenkins, 2000; Ray, 2000; Oliver \& Jenkins, 2003). Este mayor y mejor uso de los recursos locales provoca que tenga un gran potencial para crear empleo, ayudando a la eficiencia en el uso de recursos y a la retención del valor generado localmente (Jenkins, 2000). Por tanto,

Hipótesis 8: El uso endógeno de los recursos para el desarrollo turístico está positivamente relacionado con la sostenibilidad económica de la región.

El TRI pretende la existencia de complementariedad entre las actividades tradicionales de la zona y las actividades turísticas (Jenkins \& Oliver, 2001). Esto implica que turistas y residentes usen de manera conjunta los recursos existentes, viéndose éstos mejorados por la existencia del turismo además de poder operar durante todo el año (Clark \& Chabrel, 2007). Todo ello tiende a compensar el declive económico de la zona y a evitar el conflicto social (Cawley \& Gillmor, 2008). Las organizaciones que establecen lazos complementarios entre sus actividades y las turísticas tienen más probabilidades de alcanzar los objetivos económicos de generación de beneficios y de empleo locales (Ohe \& Kurihara, 2013). Así,

Hipótesis 9: La complementariedad del turismo está relacionada positivamente con la sostenibilidad económica de la región.

Hipótesis 10: La complementariedad del turismo está relacionada positivamente con la sostenibilidad sociocultural de la región.

Los resultados alcanzados a través del TRI deben ser sostenibles, esto es, deben equilibrar las aspiraciones sociales, económicas y medioambientales de las comunidades con los costes y beneficios de los stakeholders clave (Saxena et al., 2007). Se deben buscar y fomentar formas benignas de turismo que se adecuen al criterio de desarrollo económico y social del destino (Sharpley, 2000). Un turismo de pequeña escala, adecuado a los recursos existentes en la región, genera múltiples aportes a la sostenibilidad. Este turismo posee una fuerte relación con la economía local. Genera una menor fuga de rentas al exterior (Hampton, 1998, 2005), ya que predominan los negocios de propiedad local, lo que implica que los beneficios se queden en la región y que se genere empleo (Wanhill, 2000; Andriotis, 2005). Además, tiene un impacto limitado en el entorno natural y ayuda a preservar la arquitectura local y los eventos socioculturales tradicionales (Fiallo, Petrou \& Skuras, 2002). Esto hace que represente una ventaja competitiva al responder a las nuevas demandas de experiencias turísticas alternativas, permitiendo contactar a los visitantes con los residentes y su cultura (Midtgard, 2003). Todo esto provoca que los residentes formen parte del producto turístico, lo que favorece el empoderamiento de la comunidad, especialmente por la presencia de emprendimientos familiares controlados por sus dueños (Hampton, 2005). Así,

Hipótesis 11: La existencia de una escala adecuada a las infraestructuras está relacionada positivamente con la sostenibilidad económica de la región.

Hipótesis 12: La existencia de una escala adecuada a las infraestructuras está relacionada positivamente con la sostenibilidad sociocultural de la región.

Hipótesis 13: La existencia de una escala adecuada a las infraestructuras está relacionada positivamente con la sostenibilidad medioambiental de la región.

Hipótesis 14: La existencia de una escala adecuada a las infraestructuras está relacionada positivamente con el empoderamiento de la comunidad.

La implicación de los residentes resulta clave en todo este proceso (Gusoy, Chi \& Dyer, 2010). Deben comprender los objetivos que la comunidad se plantea alcanzar a través del desarrollo turístico así como las ventajas que se derivan (Sharpley, 2015). Además, deben poder tomar parte del proceso, manifestando sus opiniones y que éstas sean tenidas en cuenta. Este empoderamiento de los residentes beneficia el desarrollo del turismo e incrementa el uso sostenible de los recursos en sus tres vertientes: económica, social y medioambiental (Anderson \& Lunderg, 2013). Al tener un mayor control sobre sus propios recursos, existe una alta motivación para conservarlos y hacerlos 
sostenibles (Kellert et al., 2000). Así, la comunidad orienta sus recursos hacia la satisfacción de sus propias necesidades, mejorando el bienestar general de la región. Así,

Hipótesis 15: El empoderamiento de la comunidad está relacionado positivamente con la sostenibilidad sociocultural de la región.

Hipótesis 16: El empoderamiento de la comunidad está relacionado positivamente con la sostenibilidad económica de la región.

Hipótesis 17: El empoderamiento de la comunidad está relacionado positivamente con la sostenibilidad medioambiental de la región.

Por todo lo anterior, el modelo conceptual propuesto es el que se muestra en la Figura 1.

Figura 1. Modelo conceptual propuesto

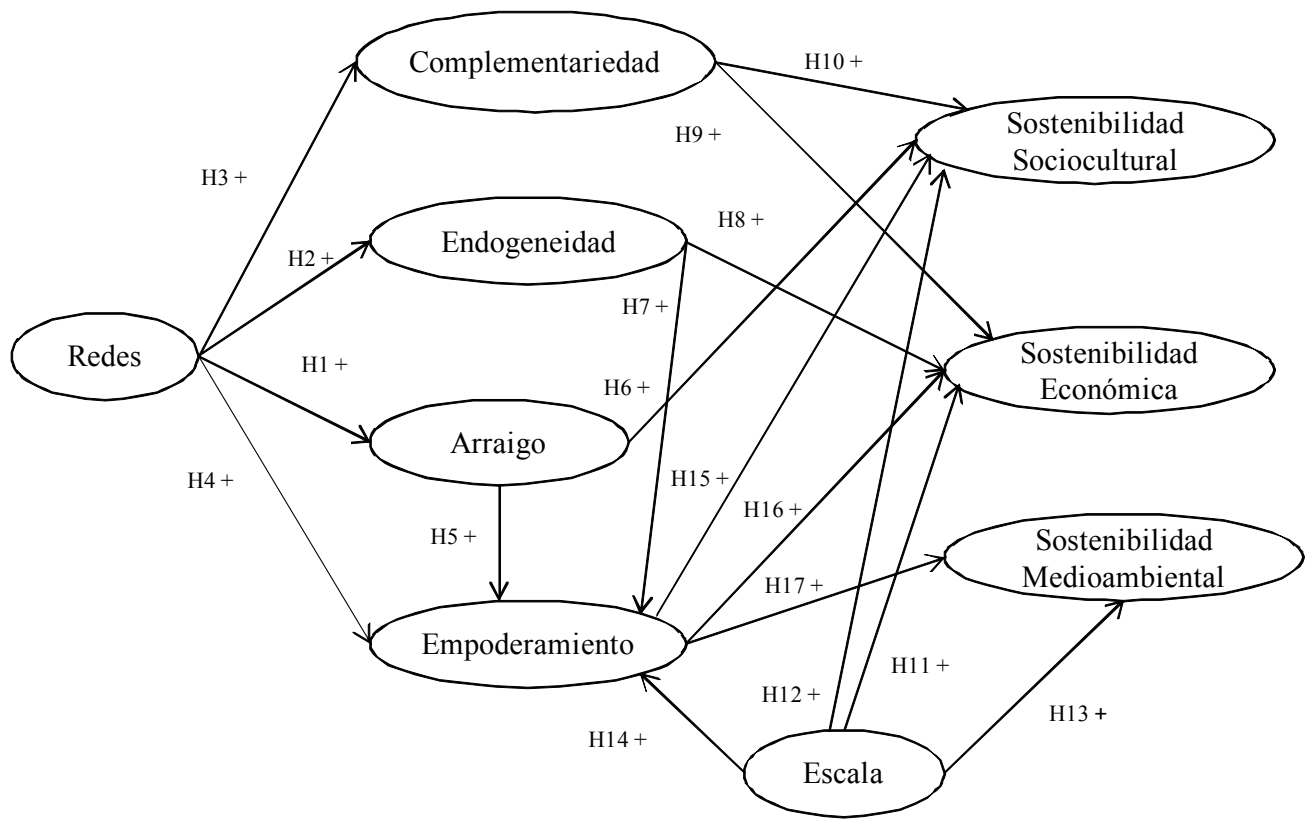

\section{Metodología}

\section{Zona bajo Estudio: Entre Ríos (Argentina)}

La provincia de Entre Ríos forma parte de la Mesopotamia Argentina (ver Figura 2). Tiene una extensión de $78.781 \mathrm{~km}^{2}$, está dividida en diecisiete departamentos y cuenta con una población de 1.235.994 habitantes. Las ciudades de mayor población son Paraná (247.863 habitantes), Concordia (152.282 habitantes) y Gualeguaychú (83.116 habitantes) (INDEC: Censo, 2010). Sus características geográficas, separadas del resto del país por el río Paraná, provocaron un fuerte aislamiento hasta finales de la década de 1960, en la que se iniciaron grandes infraestructuras viales que facilitaron su integración. A pesar del retroceso experimentando por la actividad agrícola y ganadera desde mediados del siglo XX, éstas siguen constituyendo las principales actividades económicas provinciales (Wallingre, 2008). Las actividades primarias (agrarias) participan con el $20.85 \%$ del PBI provincial y el sector manufacturero (procesador de materias primas agropecuarias) reúne el 50\% del total de establecimientos de la provincia y genera aproximadamente el 10\% del PBI provincial (http://www.entreriostotal.com. ar/industria/aspectos.htm). 
Figura 2. Mapa de la zona

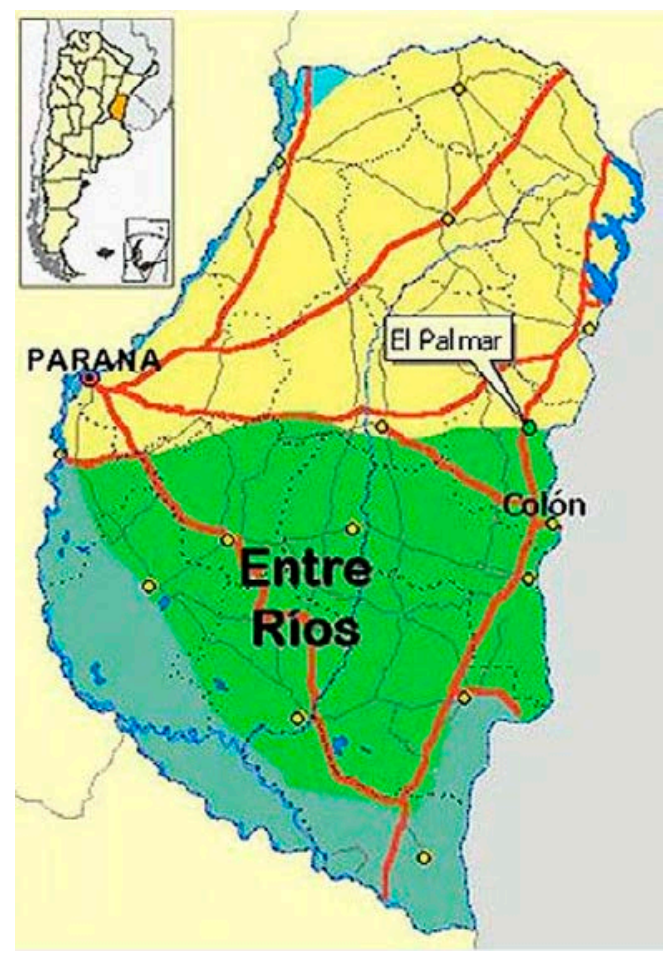

Hasta 1984 la provincia de Entre Ríos no fue incorporada a los planes de desarrollo del turismo que intentó implementar el Ministerio de Economía de Argentina. En 2005 el gobierno nacional lanzó el Plan Federal Estratégico de Turismo Sustentable 2016 (PFETS) que, para el caso de Entre Ríos, reconoce al Corredor Turístico del Rio Uruguay como prioritario. Previamente, en el 2003, el gobierno provincial había puesto en marcha un plan centrado en el turismo como alternativa de desarrollo de las economías regionales. En él se crearon distintas micro regiones turísticas articuladas por las principales localidades, rutas y accesos. Las micro regiones incluyen espacios rurales y urbanos que se complementan entre sí ya que comparten rasgos como la historia, la cultura, el paisaje o la naturaleza. Entre Ríos cuenta con 28 áreas naturales protegidas y 30 bienes culturales protegidos. Desde inicios del siglo XXI, ha experimentado un importante crecimiento como receptor del turismo interno

Entre estas micro regiones se encuentra, desde 2007, Tierra de Palmares, cuyo objetivo es un desarrollo turístico centrado en los paisajes, las termas, las playas fluviales, la historia de inmigrantes y el Parque Nacional El Palmar. Uno de sus objetivos es el desarrollo sostenible, teniendo como principios rectores el respeto de las aspiraciones de los residentes y la satisfacción de los visitantes (Gastón, 2012). La diversa oferta turística de la micro región (extensas áreas naturales, playas, aguas termales, sitios históricos-culturales, productivos, gastronómicos, recreativos y el Parque Nacional El Palmar) se agrupa configurando distintos itinerarios (http://www.tierradepalmares.tur.ar/itinerarios-turisticos-micro-regionales-tierra-de-palmares.php). Su composición es heterogénea ya que contiene a la cabecera departamental, Colón, a pueblos de significativa magnitud y a otros muy pequeños. Se pretende que el turista recorra la mayor parte de los atractivos que ofrece la micro región, cuya imagen se centra en el turismo de naturaleza dentro de Colón (Caruso, 2015). Colón es una de las principales localidades en las que se articula dicha oferta, junto con San José, Ubajay, Villa Elisa y Salvador.

El criterio estadístico censal vigente en Argentina clasifica como población rural a la que se encuentra agrupada en localidades de menos de 2.000 habitantes y a la que se encuentra dispersa en campo abierto. Sin embargo, el geógrafo argentino Reboratti (2008) indica que la nueva ruralidad en Argentina ha supuesto un cambio objetivo en las condiciones del campo que se ha manifestado en la aparición de nuevas 
condiciones sociales, tecnológicas, económicas y territoriales así como en una profunda modificación de la relación entre el campo y la ciudad, tendente a disminuir sus diferencias. El resultado es una importante metamorfosis y un crecimiento de las áreas urbanas próximas a la producción agrícola moderna, concentración de la tierra y pérdida de la población rural dispersa (Mikkelsen, 2013). Así, Castro y Reboratti (2008) proponen que el concepto de ruralidad se debe incrementar hasta localidades de 20.000 habitantes, y que se deben tener cuenta también otros criterios entre los que se encuentra la estructura ocupacional y la densidad poblacional (Sancho y Reinoso, 2012).

\section{Muestra}

La información analizada fue obtenida a través de una encuesta personal realizada a los residentes de los pueblos y ciudades de los distritos de Colón y San Salvador (Argentina).

El trabajo de campo fue realizado durante los meses de enero y febrero de 2012, se obtuvieron 377 cuestionarios válidos. Las restricciones temporales y presupuestarias llevaron al uso de un muestreo de conveniencia. El modelo conceptual propuesto en la Figura 1 se valida a través de la metodología proporcionada por los modelos de ecuaciones estructurales con variables latentes.

Las características de la muestra indican que, atendiendo al lugar de residencia, el $42.7 \%$ reside en Colón, principal ciudad de la zona, el 18.9\% en Villa Elisa, el 16.7\% en San José, el 8.8\% en San Salvador, y el $12.9 \%$ reside en otras comunidades más pequeñas (9.6\% en pueblos con menos de 1.000 habitantes). Atendiendo a los criterios establecidos por Castro y Reboratti (2008), estas localidades se pueden incluir dentro de la nueva ruralidad Argentina al tener menos de 20.000 habitantes, una densidad poblacional inferior a los $20 \mathrm{hb} / \mathrm{Km}^{2}$ y mostrar un perfil productivo agroindustrial, ya que una alta proporción del producto bruto geográfico de la provincia corresponde al sector agropecuario (ganadería, agricultura, caza y silvicultura), mientras que el sector industrial manufacturero se encuentra especializada en la agroindustria (producción de los alimentos y bebidas) (Bevilacqua, 2011). Por tanto, son territorios que incluyen población dispersa, centros rurales y centros urbanos medianos con alta proporción de Población Económicamente Activa relacionada con el sector agropecuario en sentido amplio (Castro y Reboratti, 2008).

Siguiendo con la caracterización de la muestra, el 58.4\% de la muestra tienen menos de 35 años, y hay un predominio de mujeres (64.51\%). Estas características de edad y sexo se corresponden con la distribución de la población existente en la zona (http://www.entrerios.gov.ar/). De acuerdo a los años de residencia en la zona, se puede observar que más de la mitad de la muestra (56.7\%) son residentes de larga duración, es decir, llevan residiendo en la zona desde hace más de 25 años.

\section{Medición de las variables}

Todas las variables fueron medidas utilizando escalas de Likert de 11 puntos, desde 0 "Totalmente en Desacuerdo" hasta 10 "Totalmente De acuerdo", excepto las variables sociodemográficas.

El procedimiento seguido para medir las variables bajo estudio aparece detallado en Marzo-Navarro, Pedraja-Iglesias y Vinzón $(2015,2016)$. Las variables utilizadas fueron obtenidas por los autores siguiendo los pasos propuestos por Churchill (1979), DeVellis (1991) y Lazarsfeld (1985). Estos paso implican la especificación del dominio del constructo, generación de una muestra de ítems, recolección de datos y purificación del instrumento. Los modelos de medida de las variables implicadas deben ser estimados utilizando análisis factorial confirmatorio. Este tipo de análisis permite determinar la fiabilidad de la estructura estimada. Tras confirmar los correspondientes modelos de medida analizando sus estadísticos e índices de bondad del ajuste, se podrán estimar las relaciones teóricas establecidas. Para ello, la metodología propuesta será la utilización de modelos de ecuaciones.

En el Cuadro 3 se muestran las dimensiones determinadas así como sus correspondientes indicadores (Autores, 2014; 2015). Se comprobó la estructura unidimensional de todas las variables a excepción de la dimensión Redes. Redes (F3) está integrado por dos componentes. Uno de ellos es de naturaleza informativa (F2), dado que refleja la facilidad de acceso a la información colectiva sobre las actividades turísticas que existen en la región, y otro es más colaborativo (F1), dado que se centra en las relaciones que existen entre las empresas y las instituciones, lo que da lugar al desarrollo de la actividad turística. Destacar que la existencia de la dimensión Complementariedad no se verificó. Complementariedad resultó un concepto que debe ser medido a través de dos dimensiones independientes. Una de las dimensiones se refiere a la naturaleza complementaria del desarrollo de la actividad turística (F6) y la otra dimensión refleja la necesidad de que turistas y residentes compartan los servicios existentes (F7). Esto hizo necesario modificar algunas de las hipótesis propuestas. Concretamente, la Hipótesis 3 se dividió en dos, estableciéndose los efectos positivos de las Redes sobre las dos variables indicativas 
de complementariedad (F6 y F7). Lo mismo ocurrió con las Hipótesis 9 y 10, estableciéndose los efectos de las dos variables de Complementariedad sobre la sostenibilidad económica (F11) y la Sociocultural (F12). La variable escala fue medida a través de un único indicador.

\section{Cuadro 3. Dimensiones e ítems}

\begin{tabular}{|c|c|c|}
\hline \multirow[t]{2}{*}{$\begin{array}{l}\text { F3: } \\
\text { Redes }\end{array}$} & $\begin{array}{l}\text { F1: Redes } \\
\text { Colabora- } \\
\text { tivas }\end{array}$ & $\begin{array}{l}\text { Existe colaboración entre las empresas e instituciones de la zona para la organización de } \\
\text { eventos, festivales, etc. (Fiesta de la Artesanía, de la Colonización, del Arroz, etc.) } \\
\text { Las empresas e instituciones de la región promocionan conjuntamente las actividades de } \\
\text { turismo rural } \\
\text { Las empresas e instituciones de la región colaboran en el diseño de circuitos turísticos } \\
\text { rurales } \\
\text { El gobierno municipal, provincial y/o nacional colabora con las empresas e instituciones de } \\
\text { la región para el desarrollo del turismo rural }\end{array}$ \\
\hline & $\begin{array}{l}\text { F2: Redes } \\
\text { Informati- } \\
\text { vas }\end{array}$ & $\begin{array}{l}\text { En Internet hay suficiente información sobre las actividades de turismo rural que se } \\
\text { desarrollan en la región } \\
\text { En las oficinas de turismo hay suficiente información sobre las actividades de turismo rural } \\
\text { que se desarrollan en la región } \\
\text { Es fácil obtener información sobre las actividades de turismo rural de la región }\end{array}$ \\
\hline \multicolumn{2}{|c|}{ F4: Arraigo } & $\begin{array}{l}\text { Las actividades turísticas permiten al turista experimentar la cultura y las tradiciones de } \\
\text { la zona } \\
\text { Los nombres y/o imágenes locales se emplean en las marcas de los productos turísticos de } \\
\text { la región } \\
\text { Los nombres y/o imágenes locales se emplean para promocionar las actividades turísticas } \\
\text { de la región } \\
\text { Los nombres y/o imágenes locales se emplean en las marcas de las empresas/instituciones } \\
\text { turísticas }\end{array}$ \\
\hline \multicolumn{2}{|c|}{ F5: Endogeneidad } & $\begin{array}{l}\text { En general, las empresas turísticas son propiedad de personas nacidas en la región } \\
\text { En general, las empresas turísticas son gestionadas por personas nacidas en la región } \\
\text { Los recursos naturales de la zona son el principal atractivo turístico de la misma }\end{array}$ \\
\hline \multicolumn{2}{|c|}{$\begin{array}{l}\text { F6: Actividades } \\
\text { Complementarias }\end{array}$} & $\begin{array}{l}\text { Los servicios turísticos básicos (alojamiento, comida, etc.) se complementan con actividades } \\
\text { típicas de la zona (actividades de campo, visita a productores de productos regionales, etc.) } \\
\text { Los turistas pueden participar en actividades tradicionales o típicas de la zona } \\
\text { Las actividades turísticas se basan en las actividades típicas de la zona }\end{array}$ \\
\hline \multicolumn{2}{|c|}{$\begin{array}{l}\text { F7: Uso Comparti- } \\
\text { do de recursos }\end{array}$} & $\begin{array}{l}\text { Los turistas comparten con los residentes el uso de lugares físicos de esparcimiento } \\
\text { (plazas, playas, parques, etc.) } \\
\text { Los turistas comparten con los residentes los mismos servicios públicos (sanidad, } \\
\text { seguridad, etc) } \\
\text { Los turistas comparten con los residentes los mismos servicios de ocio (bares, restaurantes, } \\
\text { etc) }\end{array}$ \\
\hline \multicolumn{2}{|c|}{$\begin{array}{l}\text { F8: Empodera- } \\
\text { miento }\end{array}$} & $\begin{array}{l}\text { El desarrollo turístico de la zona tiene en cuenta los intereses de sus residentes } \\
\text { Las instituciones y/o empresas turísticas tienen en cuenta los intereses de los residentes al } \\
\text { ofertar actividades turísticas }\end{array}$ \\
\hline \multicolumn{2}{|l|}{ Escala } & $\begin{array}{l}\text { Las actividades turísticas de la zona están distribuidas de acuerdo a las infraestructuras } \\
\text { existentes en las localidades de la región }\end{array}$ \\
\hline \multicolumn{2}{|c|}{$\begin{array}{l}\text { F11: Sostenibilidad } \\
\text { Económica }\end{array}$} & $\begin{array}{l}\text { Las actividades de turismo rural existentes en la región generan oportunidades de empleo } \\
\text { para la comunidad } \\
\text { Las actividades de turismo rural existentes en la región generan beneficios a toda la } \\
\text { comunidad } \\
\text { Las actividades de turismo rural existentes en la región permiten mejorar las } \\
\text { infraestructuras existentes } \\
\text { Las actividades de turismo rural existentes en la región mejoran la calidad de vida }\end{array}$ \\
\hline \multicolumn{2}{|c|}{$\begin{array}{l}\text { F12: Sostenibilidad } \\
\text { Sociocultural }\end{array}$} & $\begin{array}{l}\text { Las actividades de turismo rural existentes en la región ayudan a conservar la cultura e } \\
\text { identidad de la región } \\
\text { Las actividades de turismo rural existentes en la región mantienen la cultura tradicional }\end{array}$ \\
\hline \multicolumn{2}{|c|}{$\begin{array}{l}\text { F13: Sostenibilidad } \\
\text { Medioambiental }\end{array}$} & $\begin{array}{l}\text { Las actividades de turismo rural existentes en la región favorecen la conservación de los } \\
\text { recursos naturales } \\
\text { Las actividades de turismo rural existentes en la región incrementan la conciencia } \\
\text { ecológica de la sociedad } \\
\text { Las actividades de turismo rural existentes en la región favorecen el desarrollo de acciones } \\
\text { dirigidas al mantenimiento del medio ambiente }\end{array}$ \\
\hline
\end{tabular}

Fuente: Marzo-Navarro, Pedraja-Iglesias y Vinzón (2015, 2016) 


\section{Resultados}

La estimación del modelo propuesto, al cual se le incorporaron las modificaciones derivadas de los modelos de medida de las variables bajo estudio, presenta los resultados reflejados en la Tabla 1 y en la Tabla 2. La estimación obtenida proporcionó una chi-cuadrado de Satorra-Bentler de 679.1260, con 442 grados de libertad y un p-value de 0.00000. Los índices y estadísticos de bondad del ajuste son los mostrados en la Tabla 1, y como se puede observar, toman valores adecuados. Además, respecto a los modelos de medida de los conceptos teóricos, como se observa en la Tabla 2 los coeficientes de fiabilidad CF1 (Fornell \& Larker) y CF2 (Omega) ofrecen evidencia de validez interna de las variables latentes bajo análisis.

Tabla 1. Estadísticos e índices de bondad del ajuste

\begin{tabular}{lllllllll}
\hline gl & $\chi_{\text {S.B }}^{2}$ & $p$ & R-RMSEA & SRMR & GFI & AGFI & R-BBN & R-CFI \\
\hline 442 & 679.1260 & 0.00000 & 0.040 & 00.074 & 0.849 & 0.820 & 0.837 & 0.935 \\
\hline
\end{tabular}

Tabla 2. Coeficientes de Validez Interna

\begin{tabular}{lll}
\hline & CF1 & CF2 \\
\hline F1: Redes Colaborativas & 0,48 & 0,78 \\
\hline F2: Redes Informativas & 0,62 & 0,83 \\
\hline F4: Arraigo & 0,33 & 0,65 \\
\hline F5: Endogeneidad & 0,53 & 0,77 \\
\hline F6: Actividades Complementarias & 0,61 & 0,76 \\
\hline F7: Uso compartido de recursos & 0,53 & 0,77 \\
\hline F8: Empoderamiento & 0,67 & 0,80 \\
\hline F11: Sostenibilidad económica & 0,59 & 0,85 \\
\hline F12: Sostenibilidad sociocultural & 0,72 & 0,84 \\
\hline F13: Sostenibilidad medioabiental & 0,72 & 0,88 \\
\hline
\end{tabular}

Los resultados obtenidos de la estimación del modelo permiten no rechazar la mayoría de las hipótesis propuestas, tal y como se muestra en la Tabla 3. Así, las Hipótesis 1, 2, 3 y 4 son aceptadas, quedando comprobados los efectos positivos y significativos que la colaboración entre los distintos agentes implicados en el desarrollo turístico, plasmada a través del concepto amplio de Redes, ejerce sobre el desarrollo de un turismo arraigado, endógeno, complementario a las actividades tradicionales y que permite el uso compartido de los recursos por residentes y turistas. Además, estas redes incrementan el empoderamiento de los residentes.

La Hipótesis 5 no puede ser aceptada, por lo que no se comprueba el efecto del desarrollo de un turismo arraigado con el incremento del empoderamiento de los residentes. La explicación a este resultado puede encontrarse en los indicadores que finalmente entraron a formar parte del modelo de medida de la variable arraigo. Dicho indicadores se centran en el uso de señales locales en el nombre de los productos y actividades ofertados y en que los turistas experimenten las tradiciones de la zona. Por el contrario, sí que puede ser aceptada la Hipótesis 6, ya que resulta lógico que el arraigo, tal y como ha sido medido, afecte a la sostenibilidad sociocultural.

En contra de lo esperado los resultados no permiten aceptar la Hipótesis 7, por lo que no queda demostrado el efecto del desarrollo de actividades turísticas endógenas en el empoderamiento de los residentes. El hecho que las empresas turísticas existentes pertenezcan, sean gestionadas y financiadas por capital humano de la zona no resulta significativo a la hora de que el resto de residentes perciban que se están teniendo en cuenta sus intereses. Sin embargo, a un nivel de confianza del 90\%, los resultados permiten aceptar la Hipótesis 8, quedando demostrado el efecto del desarrollo de actividades turísticas endógenas en la sostenibilidad económica. De este modo, que las empresas turísticas sean propiedad, estén gestionadas y sean financiadas por capital humano de la zona sí que afecta positivamente a que el resto de residentes perciban una mejora en las oportunidades de empleo, los beneficios para la 
comunidad y la calidad de vida. Estos resultados pueden deberse a que la zona analizada se encuentra en las fases iniciales del proyecto de desarrollo turístico. Así, los beneficios generados hasta el momento afectan más directamente a las personas implicadas en las actividades turísticas pero que, en general, los intereses del resto de residentes no se hayan visto afectados.

Las Hipótesis 9 y 10, relacionadas con la Complementariedad, tuvieron que ser modificadas al no verificarse la existencia de la variable. Recordemos que si se comprobó la existencia de dos variables independientes relacionadas con la complementariedad de las actividades tradicionales y turísticas (F6) y con el uso compartido de recursos por residentes y turistas (F7). Así, se establecieron las mismas hipótesis pero para cada una de estas variables. Los resultados obtenidos permiten aceptar las cuatro hipótesis establecidas. Así, tanto la existencia de actividades turísticas complementarias a las tradicionales afecta positivamente a la sostenibilidad económica (H9) y la sostenibilidad sociocultural (H10). Igualmente, el uso compartido de los recursos afecta positivamente a la sostenibilidad económica (H9a) y a la sostenibilidad sociocultural (H10a). A pesar de no comprobarse la estructura unidimensional de la complementariedad, quedan comprobados los efectos positivos que tanto el uso compartido de recursos como el diseño de actividades turísticas que complementan a las tradicionales de la zona generan beneficios económicos para la comunidad, y ayudan a conservar el entorno sociocultural.

Ninguna de las Hipótesis relacionadas con la variable Escala (H11, H12, H13 y H14) puede ser aceptada. Parece que en el caso analizado la adecuación entre la escala y el desarrollo turístico alcanzado actúa como una variable moderadora y que, implícitamente, ya esté actuando sobre el modelo. Como ya se ha destacado, en el momento de realización de la encuesta, la zona analizada se encontraba en las fases iniciales del desarrollo turístico, por lo que no se haya llegado a un punto de saturación de los recursos existentes.

Finalmente, se verifican las hipótesis relacionadas con los efectos del empoderamiento de los residentes (H15, H16, H17). Se corrobora como el hecho de tener en cuenta las opiniones e intereses de los residentes afecta positivamente al desarrollo sostenible. El apoyo de los residentes hace que se mantengan los beneficios económicos en la zona, se preserve la cultura y la identidad local, y se preserven los recursos naturales creando además una mayor conciencia ecológica. El mayor efecto del empoderamiento de los residentes se observa sobre la sostenibilidad medioambiental, seguido de la económica y la sociocultural.

Tabla 3. Coeficientes e hipótesis

\begin{tabular}{|c|c|c|}
\hline HIPÓTESIS & & $\begin{array}{c}\text { Coeficiente } \\
\text { estandarizado }\end{array}$ \\
\hline H1: Redes (F3) $\rightarrow$ Arraigo (F4) & Aceptada & $0.755^{* * *}$ \\
\hline H2: Redes (F3) $\rightarrow$ Endogeneidad (F5) & Aceptada & $0.644^{* * *}$ \\
\hline H3: Redes (F3) $\rightarrow$ Actividades Complementarias (F6) & Aceptada & $0.688^{* * *}$ \\
\hline H3a: Redes (F3) $\rightarrow$ Uso Compartido de Recursos (F7) & Aceptada & $0.339^{* * *}$ \\
\hline H4: Redes (F3) $\rightarrow$ Empoderamiento (F8) & Aceptada & $0.677^{* * *}$ \\
\hline H5: Arraigo (F4) $\rightarrow$ Empoderamiento (F8) & Rechazada & \\
\hline H6: Arraigo (F4) $\rightarrow$ Sostenibilidad Sociocultural (F12) & Aceptada & $0.218^{* *}$ \\
\hline H7: Endogeneidad (F5) $\rightarrow$ Empoderamiento (F8) & Rechazada & \\
\hline H8: Endogeneidad (F5) $\rightarrow$ Sostenibilidad Económica (F11) & Aceptada & $0.139^{*}$ \\
\hline H9: Actividades Complementarias $(\mathrm{F} 6) \rightarrow$ Sostenibilidad Económica (F11) & Aceptada & $0.180 * * *$ \\
\hline H9a: Uso Compartido de Recursos (F7) $\rightarrow$ Sostenibilidad Económica (F11) & Aceptada & $0.139^{* * *}$ \\
\hline H10: Complementary Activities (F6) $\rightarrow$ Sostenibilidad Sociocultural (F12) & Aceptada & $0.281^{*}$ \\
\hline H10a: Uso Compartido de Recursos (F7) $\rightarrow$ Sostenibilidad Sociocultural (F12) & Aceptada & $0.182^{* * *}$ \\
\hline H11: Escala (V39) $\rightarrow$ Sostenibilidad Económica (F11) & Rechazada & \\
\hline H12: Escala (V39) $\rightarrow$ Sostenibilidad Sociocultural (F12) & Rechazada & \\
\hline H13: Escala (V39) $\rightarrow$ Sostenibilidad medioambiental (F13) & Rechazada & \\
\hline H14: Escala (V39) $\rightarrow$ Empoderamiento (F8) & Rechazada & \\
\hline H15: Empoderamiento (F8) $\rightarrow$ Sostenibilidad Económica (F11) & Aceptada & $0.281^{* * *}$ \\
\hline H16: Empoderamiento (F8) $\rightarrow$ Sostenibilidad Sociocultural (F12) & Aceptada & $0.349^{* * *}$ \\
\hline H17: Empoderamiento (F8) $\rightarrow$ Sostenibilidad medioambiental (F13) & Aceptada & $0.437 * * *$ \\
\hline
\end{tabular}

${ }^{*} \mathrm{p}<0.1 ;{ }^{* *} \mathrm{p}<0.05 ; * * * \mathrm{p}<0.01$ - Fuente: Elaboración propia 


\section{Conclusiones}

El turismo constituye una actividad económica que debería ayudar al desarrollo de determinadas zonas rurales. Dichas zonas deben poseer recursos sobre los cuales planificar estratégicamente el desarrollo turístico. Estos recursos pueden ser cualquier elemento natural, objeto cultural o hecho social que pueda ser utilizado como causa suficiente para motivar un desplazamiento turístico. Por tanto, constituyen el principal componente del producto turístico, al determinar la selección del destino del viaje. Pero, se debe tener en cuenta que el desarrollo turístico genera tanto efectos positivos como negativos. En términos generales, en un espacio rural el desarrollo turístico debe permitir conservar la propia esencia del territorio. Es decir, se debe conseguir un desarrollo sostenible que permita la conservación de los recursos en los que se basa (naturales y/o culturales), y en mejorar la calidad de vida de los residentes. Para ello, la integración de las distintas dimensiones que permiten dicho desarrollo resulta vital.

El Turismo Rural Integrado proporciona un enfoque que permite este desarrollo sostenible a partir de la integración de los distintos elementos que intervienen. Así, la cooperación entre los agentes implicados, la endogeneidad de los recursos empleados, el arraigo de las actividades así como su complementariedad con las actividades tradicionales de la zona deben ser los elementos clave a la hora de realizar la planificación estratégica de un proyecto turístico. A esto hay que añadirle la adecuación entre los recursos existentes y el impacto del desarrollo que se pretende. Esto es, la escala de desarrollo perseguida. Toda esta planificación no puede ser llevada a cabo con éxito si no se tiene en cuenta la opinión de los residentes en la zona. Comprender su perspectiva facilita la implantación de medidas que minimicen los efectos negativos del turismo y que maximicen sus beneficios, consiguiendo así un desarrollo turístico rural integrado.

La investigación realiza constituye un importe avance dentro del desarrollo de un Turismo Rural Integrado. El TRI supone un enfoque holístico y multidisciplinar del fenómeno turístico que incluye el estudio de los recursos, de los stakeholders involucrados y de las relaciones que se establecen entre ellos. Se ha propuesto y validado un modelo que interrelaciona las dimensiones propuestas por la literatura especializada. En general, la mayor parte de las investigaciones realizadas analizan las dimensiones bajo análisis desde una perspectiva cualitativa, sin verificar empíricamente las relaciones entre ellas. El modelo propuesto permite a los gestores turísticos ser conscientes de la complejidad de las relaciones, de la diversidad de agentes y recursos que intervienen en el desarrollo del turismo rural y de cuáles son los elementos esenciales que favorecen el desarrollo del turismo en forma sostenible, a través de este marco de análisis y gestión integral. En definitiva, generar un destino turístico que pueda ser disfrutado por residentes y visitantes. Un turismo en el que se refuercen las conexiones entre empresas, instituciones e individuos, que mantenga las tradiciones locales, que se ha adecuado a las estructuras existentes, que acompañe a las actividades productivas tradicionales, que se lleve a cabo con sus propios recursos reteniendo los beneficios en la región, que proteja los recursos naturales, que se lleve a cabo con la participación y compromiso de la comunidad local, atendiendo a sus demandas e intereses, y por tanto, que tienda a mejorar el sistema económico, sociocultural y ambiental de la comunidad como un todo. La investigación realizada pone de manifiesto que los residentes perciben la existencia de las variables necesarias para el desarrollo del TRI así como algunas de las interrelaciones existentes entre ellas.

Se ha comprobado el papel vital que, desde la perspectiva de los residentes, desempeña la colaboración entre los distintos agentes implicados como punto de partida para conseguir un TRI. En general, el tamaño de los recursos de capital y de capital humano presentes en el entorno rural provoca que sin dicha colaboración no se puedan integrar el resto de dimensiones. Así, las redes facilitan el desarrollo de un tipo de turismo endógeno, arraigado y complementario a las actividades tradicionales de la zona, en el cual se deben tener en cuenta las opiniones y los intereses de los residentes. Este empoderamiento de los residentes ha resultado clave para poder alcanzar los objetivos de sostenibilidad. Los residentes de la zona son los principales interesados en que se mantenga la esencia de su zona, ya que constituye el principal reclamo para que los turistas experimenten nuevas sensaciones. Así, mantener los recursos naturales y socioculturales resultan aspectos clave del desarrollo perseguido, consiguiendo que los beneficios económicos derivados de dicho desarrollo redunden en la zona, mejorando la calidad de vida de los residentes.

A pesar del importante paso dado con esta investigación, presenta limitaciones que deben ser tenidas en cuenta y que dan lugar a futuras líneas de investigación. Así, la zona analizada se encuentra en las fases iniciales del desarrollo turístico, por lo que muchos de los efectos negativos del turismo pueden aún no haber sido percibidos por los residentes. Estos residentes pueden encontrarse dentro de la denominada etapa de euforia (Doxey, 1976; Upchurch \& Teivane, 2000), en la cual acogen a los 
visitantes con entusiasmo y perciben al turismo como una buena opción de desarrollo. Esto se puede ver corroborado con la falta de efectos significativos ejercidos por la dimensión Escala. Así, parece que o el volumen de turistas en la zona se mantiene dentro de unos límites razonables de capacidad de carga o que, aunque se haya superado, la población local aún no ha comenzado a dar signos de frustración y de descontento con el turismo que se está desarrollando. Destacar que el número de visitantes al Parque Nacional El Palmar se ha incrementado en más de 50.000 desde la creación de la micro región Tierra de Palmares, situándose en el año 2012 en torno a los 175.000 visitantes. Esto puede afectar a su degradación ambiental, poniendo en peligro el ecosistema que se promociona de manera turística (Caruso, 2015). Por tanto, sería interesante analizar el modelo en zonas en las cuales el desarrollo turístico sea mayor. Además, sería interesante analizar la perspectiva de otros stakeholders y realizar una comparativa entre sus distintas percepciones. Finalmente, aunque las características de la muestra no permiten extrapolar los resultados, también es cierto que cada zona presenta características propias que hacen difícil conseguir un modelo general de TRI aplicable a cualquier destino. Por ejemplo, la información analizada proviene de una zona rica fundamentalmente en recursos naturales, los cuales sirven de punto de partida como reclamo turístico, con un desarrollo de infraestructuras determinado. En otras zonas, estas circunstancias pueden diferir, por lo que las relaciones significativas pueden ser otras. Esto no resta valor al modelo propuesto, el cual puede servir de partida para investigaciones futuras.

\section{Bibliografia}

Andereck, K.L. \& Vogt, C.A.

2000. "The Relationship between Residents' Attitudes toward Tourism and Tourism Development Options". Journal of Travel Research, 39: 27-36. doi: 10.1177/004728750003900104

Alonso-Almedia, M.M. \& Celemín-Pedroche, M.S.

2016. "Competitividad y Destinos Turísticos Sostenibles". Esic Market Economics and Business Journal, 47(2): 291-306. doi: 10.7200/esicm.153.0472.3e

Anderson, T.D. \& Lundberg, E.

2013. "Commensurability and Sustainability: Triple Impact Assessments of a Tourism Event". Tourism Management, 37(1), 99-109. http://dx.doi.org/10.1016/j.tourman.2012.12.015

Almeida, F., Peláez, M.J., Balbuena, A. \& Cortés, R.

2016. "Residents' Perceptions of Tourism Development in Benalmádena (Spain)". Tourism Management,

54: 259-274. http://dx.doi.org/10.1016/j.tourman.2015.11.007

Andriotis, K.

2005. 'Community Groups' Perceptions of and Preferences for Tourism Development: Evidence from

Crete". Journal of Hospitality and Tourism Research, 29(1), 67-90. doi: 10.1177/1096348004268196 Avila, R. \& Barrado, D.A.

2005. "Nuevas Tendencias en el Desarrollo de Destinos Turísticos: Marcos Conceptuales y Operativos para su Planificación y Gestión”. Cuadernos de Turismo, 15, 27-43. ISSN: 1139-7861.

Bandura, A.

1977. "Self-Efficiency: Toward a Unifying Theory of Behavioral Change". Psychological Review, 84(2): $191-215$

Barcus, $\mathrm{H}$.

2013). "Sustainable Development or Integrated Rural Tourism?. Considering the Overlap in rural

Development Strategies". Journal of Rural and Community Development, 8(3): 127-143.

Barke, M.

2004. "Rural Tourism in Spain". International Journal of Tourism Research, 6(3): 137-149.

Bassand, M.

1993. Culture and Regions of Europe. ISBN 92-871-2159-1

Bevilacqua, M.L.

2011. Políticas Públicas para el Desarrollo Productivo de Entre Ríos: Asimetrías y Proceso de Convergencia en la Región Centro Argentina, Tesis Doctoral, Universidad Internacional de Andalucía.

Bramwell, B. \& Lane, B.

2000. Tourism Collaboration and Partnerships: Politics, Practice and Sustainability. Sydney: Channel View. 
Byrd, E., Bosley, H. \& Dronberger, M.

2009. "Comparisons of Stakeholder Perceptions of Tourism Impacts in Rural Eastern North Carolina".

Tourism Management, 30: 693-703. http://dx.doi.org/10.1016/j.tourman.2008.10.021

Caruso, S.

2015. "Incidencia del Turismo en el Riesgo Ambiental del Parque Nacional El Palmar". Folia Histórica del Nordeste, 22: 115-139.

Castro, H. \& Reboratti, C.

2008): Revisión del Concepto de Ruralidad en la Argentina y Alternativas Posibles para su Redefinición. Serie Estudios e Investigaciones N ${ }^{\circ} 15$, Ministerio de Economía y Producción Secretaría de Agricultura, Ganadería, Pesca y Alimentos Dirección de Desarrollo Agropecuario PROINDER Buenos Aires.

Cawley, M. \& Gillmor, D.

2008. "Integrated Rural Tourism. Concepts and Practice". Annals of Tourism Research, 35(2), pp. 316-337. http://dx.doi.org/10.1016/j.annals.2007.07.011

Churchill, G.A. Jr.

1979. "A Paradigm for Developing Better Measures of Marketing Constructs". Journal of Marketing Research, 16: 64-73. http://www.jstor.org/stable/3150876

Clark, G. \& Chabrel, M.

2007). Measuring Integrated Rural Tourism. Tourism Geographies, 9, 371-386.

Comisión Europea

1988. El Futuro del Mundo Rural. Madrid, MAPA. ISBN 92-825-9069-0

DeVellis, R.F.

1991. Scale Development. Theory and Applications. Newbury Park, CA: Sage.

Deery, M., Jagb, L. \& Fredline, L.

2012. "Rethinking Social Impacts of Tourism Research: A New Research Agenda". Tourism Management, 33(1), 64-73. http://dx.doi.org/10.1016/j.tourman.2011.01.026

Doxey, G.

1976. "When Enough is Enough: the Natives are Restless in Old Niagara". Heritage Canada, 2(2): 26-27.

Dyer, P., Gursoy, D., Sharma, B. \& Carter, J.

2007. "Structural Modeling of Resident Perceptions of Tourism and Associated Development on the Sunshine Coast, Australia". Tourism Management, 28: 409-422. http://dx.doi.org/10.1016/j. tourman.2006.04.002

Fiallo, E., Petrou, A. \& Skuras, D.

2002. Consolidated Analytical Review of Resources and Activities (SPRITE), Patras, Department of Economics, University of Patras.

Galloway, L., Sanders, J. \& Deakins, D.

2011. "Rural Small Firms' Use of the Internet: From Global to Local". Journal of Rural Studies, 27: 1-9. http://dx.doi.org/10.1016/j.jrurstud.2011.05.005

Garín, A.

2015. Turismo Rural en el Acomuna de Villarica - Chile. Institucionalidad y Emprendedores Rurales. Estudios y Perspectivas en Turismo, 24: 21-39

Gaston, F.

2012. Asociativismo Intermunicipal como Estrategia de Desarrollo del Turismo. Estudio de Caso: Microregión "Tierra de Palmares", provincia de Entre Ríos (Argentina), en Actas del $5^{\circ}$ Congreso Latino-Americano de Investigación Turística, 3-5 de septiembre, Sao Paulo (Brasil).

Ghaderi, Z. \& Henderson, J.C.

2012. "Sustainable rural Tourism in Iran: A Perspective from Hawraman Village". Tourism Management Perspectives, 2-3: 47-54. http://dx.doi.org/10.1016/j.tmp.2012.03.001

Giarracca, N.

2001. ¿Una Nueva Ruralidad en América Latina?. Buenos Aires: Clacso.

Granovetter, M.

1985. "Economic Action and Social Structure: The Problem of Embeddedness". American Journal of Sociology, 91: 481-510. http://www.jstor.org/stable/2780199

Gursoy, D., Chi, C.G. \& Dyer, P.

2010. "Locals'Attitudes toward Mass and Alternative Tourism: the Case of Sunshine Coast, Australia". Journal of Travel Research, 49(3): 381-394. doi: 10.1177/0047287509346853 
Hampton, M.

1998. "Backpacker Tourism and Economic Development". Annals of Tourism Research, 25: 639-660. http://dx.doi.org/10.1080/00049182.2015.1074783

Hampton M.

2005. "Heritage, Local Communities and Economic Development". Annals of Tourism Research, 32(3): 735-759. http://dx.doi.org/10.1016/j.annals.2004.10.010

INDEC

2010. http://www.indec.gov.ar/censos_provinciales.asp?id_tema_1=2\&id_tema_2=41\&id_tema_3=135 $\& p=30 \& d=008 \& \mathrm{t}=3 \& \mathrm{~s}=0 \& \mathrm{c}=2010$

Ilbery, B., Saxena, G. \& Kneafsey, M.

2007. "Exploring Tourists and Gatekeepers'Attitudes Towards Integrated Rural Tourism in the England-Wales Border Region”. Tourism Geographies, 9(4): 441-468. http://dx.doi.org/10.1080/14616680701647667 Jamal, T. \& Kim, H.

2005. "Bridging the Interdisciplinary Divide: Towards an Integrated Framework for Heritage Tourism Research”. Tourist Studies, 5(1): 55-83. doi: 10.1177/1468797605062715

Jenkins, $\mathrm{T}$.

2000. "Putting Postmodernity into Practice: Endogenous Development and the Role of Traditional Cultures in the Rural Development of Marginal Regions". Ecological Economics, 34: 301-314. http:// dx.doi.org/10.1016/S0921-8009(00)00191-9

Jenkins, T. \& Oliver T.

2001. Integrated Tourism: A Conceptual Framework. Deliverable 1 SPRITE Project. Aberystwyth: Institute of Rural Studies.

Jurowski, C. \& Gursoy, D.

2004. "Distance Effects on Residents' Attitudes Toward Tourism". Annals of Tourism Research, 31(2), 296-312. http://dx.doi.org/10.1016/j.annals.2003.12.005

Kalantaridis, C. \& Bifka, Z.

2006. "Local Embeddedness and Rural Entrepreneurship: Case-Study Evidence from Cumbria, England". Environment and Planning A, 38: 1561-1579. doi: 10.1068/a3834

Kastenholz, E., Carneiro, M.J., Marques, C.P. \& Lima, J.

2012. Understanding and Managing the Rural Tourism Experience. The Case of a Historical Village in Portugal, Tourism Management Perspectives, 4: 207-214. http://dx.doi.org/10.1016/j.tmp.2012.08.009

Kellert S.R; Mehta J.N; Ebbin S.A. \& Lichtenfeld L.L.

2000. „Community Natural Resource Management: Promises, Rhetoric, and Reality”. Society and Natural Resources, 13: 705-715. http://dx.doi.org/10.1080/089419200750035575

Kneafsey, M.

2001. "Rural Cultural Economy: Tourism and Social Relations". Annals of Tourism Research, 28(3): 762-783. http://dx.doi.org/10.1016/S0160-7383(00)00077-3

Kim, K., Uysal, M \& Sirgy, M.

2013. "How does tourism in a Community Impact the Quality of Life of Community Residents?". Tourism Management, 36, 527-540. http://dx.doi.org/10.1016/j.tourman.2012.09.005

Lazarsfeld, P.

1985. De los Conceptos a los Índices Empíricos, in Lazarsfeld \& R.Boston (eds.). Metodología de las Ciencias Sociales, 1: 35-62. Barcelona: Spain.

Lee, T.

2013. "Influence Analysis of Community Resident Support for Sustainable Tourism Development". Tourism Management, 34(1), 37-46. http://dx.doi.org/10.1016/j.tourman.2012.03.007

Long, N. \& Van der Ploeg, J.

1994. Heterogeneity, Actor and Structure: Towards a Reconstitution of the Concept of Structure, in Booth, D. (Ed.) Rethinking Social Development: Theory, Research and Practice, Harlow: Longman Scientific and Technical.

Marzo-Navarro, M., Pedraja-Iglesias, M y Vinzón, L.

2015. "Sustainability indicators of rural tourism from the perspective of the residents". Tourism Geographies, 17(4), 586-602. http://dx.doi.org/10.1080/14616688.2015.1062909

Marzo-Navarro, M., Pedraja-Iglesias, M y Vinzón, L.

2016. "Development and Validation of the Measurement Instruments of the Determinant Elements of Integrated Rural Tourism”. Journal of Hospitality \& Tourism Research, 40(4), 476-496 
Midtgard, M.

2003. Authenticity: Tourist Experiences in the Norwegian Periphery, In New Directions in Rural Tourism,

D. Hall, L. Roberts and M. Saxena 1, (Eds.), 102-114, Aldershot: Ashgate.

Mikkelsen, C.A.

2013. "Debatiendo lo Rural y la Ruralidad: un aporte desde el Sudeste de la provincia de Buenos Aires, el caso del partido de Tres Arroyos". Cuadernos de Geografía: Revista Colombiana de Geografía, 22(2): 235-256. http://www.revistas.unal.edu.co/index.php/rcg/rt/printerFriendly/30993/43850

Muñoz de Escalona, F.

1994. "Turismo Rural Integrado: una fórmula Innovadora basada en un Desarrollo Científico". Estudios Turísticos, 121, 5-25.

Navarro, D.

2015. "Recursos Turísticos y Atractivos Turísticos: Conceptualización, Clasificación y Valoración". Cuadernos de Turismo, 35, 335-357.

Nunkoo, R. \& Gursoy, D.

2011. "Residents' Support for Tourism: an Identity Perspective". Annals of Tourism Research, 39(1), 243-268. http://dx.doi.org/10.1016/j.annals.2011.05.006

Ohe, Y. \& Kurihara, S.

2013. "Evaluating the Complementary Relationship between Local Brand Farm Products and Rural Tourism: Evidence from Japan”. Tourism Management, 35: 278-283. http://dx.doi.org/10.1016/j. tourman.2012.07.003

Oliver, T. \& Jenkins, T.

2003. "Sustaining Rural Landscapes: The Role of Integrated Tourism". Landscape Research, 28(3): 293-307. http://dx.doi.org/10.1080/01426390306516

Oxaal, Z. \& Baden, S.

1997. Gender and Empowerment: Definitions, Approaches and Implications for Policy, Briefing Prepared for the Swedish International Development Cooperation Agency (SIDA), Brighton: Institute of Development Studies.

Panyik,E. Costa, C. \& Rátz, T.

2011. "Implementing Integrated Rural Tourism: An Event-Based Approach". Tourism Management, 32 : 1352-1363. http://dx.doi.org/10.1016/j.tourman.2011.01.009

Park, D.B. \& Yoon, Y.S.

2011. "Developing Sustainable Rural Tourism Evaluation Indicators". International Journal of Tourism Research, 13: 401-415. 10.1002/jtr.804

Pavlovich, K.

2003. "The Evolution and Transformation of a Tourism Destination Network: The Waitomo Caves, New Zealand". Tourism Management, 24(2), 203-216. http://dx.doi.org/10.1016/S0261-5177(02)00056-0

Pérez, E. \& Nadal, J.

2005. "Host Community Perceptions: a Cluster Analysis". Annals of Tourism Research, 32(4), 925-941. http://dx.doi.org/10.1016/j.annals.2004.11.004

Pérez, C. \& Zizumbo, L.

2014. "Turismo rural y comunalidad: impactos socioterritoriales en San Juan Atzingo, México". Cuadernos de Desarrollo Rural, 11(73): 17-38.

Petrou, A.; Pantziou, E.; Dimara, E. \& Skuras, D.

2007. "Resources and Activities Complementarities: the Role of Business Networks in the Provision of Integrated Rural Tourism". Tourism Geographies, 9(4): 421-440. http://dx.doi.org/10.1080/14616680701647634

Pitarch, M.D., Buciega, A. \& Esparcia, J.

2004. El Turismo Integrado. Repercusiones Sociales en Áreas Rurales, en actas del VIII Congreso Español de Sociología: Turismo, Ocio y Deporte, Alicante, 23-25 septiembre. ISBN: 84-9749-121-1, pp. 247-268.

Prats, Ll.

1997. Antropología y Patrimonio. $1^{a}$ edición. Editorial Ariel, S.A. Barcelona. ISBN: 978-84-344-2211-7, Ray, C.

2000. "Endogenous Socio-Economic Development in the European Union e Issues of Evaluation". Journal of Rural Studies, 16(4): 447-458. DOI: 10.1016/S0743-0167(00)00012-7

Reboratti, C.

2008. Los Nuevos Productores: Alimentos de Alto Valor y Reestructuración Agraria, ed. Clara Craviotti, 15-18, Buenos Aires: CICCUS. 
Rojas, H.

2009. "Entre lo ideal y lo real; ¿los cambios en los enfoques propuestos de turismo rural sostenible desde la Organización de las Naciones Unidas contribuirían al desarrollo rural territorial?". Cuadernos de Desarrrollo Rural, 6(62): 145-171.

Ruiz, E. \& Hernández M.

2010. "Tourism that Empowers?: Commodification and Appropriation in Ecuador's Turismo Comunitario". Critique of Anthropology, 30(2): 201-229. doi: 10.1177/0308275X09345426

Sancho, J. \& Reinoso, D.

2012. "La Delimitación del Ámbito Rural: una Cuestión Clave en los Programas de Desarrollo Rural". Estudios Geográficos, LXXIII (273): 599-624. doi: 10.3989/estgeogr.201221

Saxena, G.

2005. "Relationships, Networks and the Learning Regions: Case Evidence from the Peak District National Park". Tourism Management, 26: 277-289. http://dx.doi.org/10.1016/j.tourman.2003.11.013 Saxena, G. \& Ilbery, B.

2008. "Integrated Rural Tourism: A Border Case Study". Annals of Tourism Research, 35(1): 233-254. http://dx.doi.org/10.1016/j.annals.2007.07.010

Saxena, G.; Clark, G.; Oliver, T. \& Ilbery, B.

2007. "Conceptualizing Integrated Rural Tourism”. Tourism Geographies, 9(4): 347-370. dx.doi. org/10.1080/14616680701647527

Sharpley, R.

2000. "Tourism and Sustainable Development: Exploring the Theoretical Divide". Journal of Sustainable Tourism, 8(1): 1-19. http://dx.doi.org/10.1080/09669580008667346

Sharpley, R.

2003. Rural Tourism and Sustainability: A Critique, in D. Hall, L. Roberts \& M. Mitchell (Eds), New Directions in Rural Tourism, Burlington, VT: Ashgate Publishing.

Sharpley, R.

2015. "Host Perceptions of Tourism: A Review of the Research". Tourism Management, 42: 37-49. http:// dx.doi.org/10.1016/j.tourman.2013.10.007

Simao, J.N. \& Partidário, M.R.

2012. "How Does Tourism Planning Contribute to Sustainable Development?". Sustainable Development, 20(6): 372-385. doi:10.1002/sd.495

Sims, R.

2010. "Putting Place on the Menu: The Negociation of Locality in U.K Food Tourism, from Production to Consumption". Journal of Rural Studies, 26(2): 105-115. http://dx.doi.org/10.1016/j.jrurstud.2009.09.003 Sinclair, G., Gursoy, D. \& Vieregge, M.

2015. "Residents' perceptions toward tourism development: A factor-cluster approach". Journal of Destination Marketing \& Management, 4, 36-45. http://dx.doi.org/10.1016/j.jdmm.2014.10.001

Stamboulis, Y. \& Skayannis, P.

2003. "Innovation Strategies and Technology for Experience-Based Tourism". Tourism Management, 24: 35-43. http://dx.doi.org/10.1016/S0261-5177(02)00047-X

Tsaur, S.H, Lin, C.H. \& Lin, J.H.

2006. "Evaluating Ecotourism Sustainability from the Integrated Perspective of Resource, Community and Tourism". Tourism Management, 27: 640-653. http://dx.doi.org/10.1016/j.tourman.2005.02.006 Upchurch, R.S. \& Teivane, U.

2000. Resident Perceptions of Tourism Development in Riga, Latvia. Tourism Management, 21(5), 499-507. http://dx.doi.org/10.1016/S0261-5177(99)00104-1

Vargas, A., Plaza, M. \& Porras, N.

2009. "Understanding Residents'Attitudes toward the Development of Industrial Tourism in a Former Mining Community". Journal of Travel Research, 47(3): 373-387. doi: 10.1177/0047287508322783

Wallingre, $\mathrm{N}$.

2008. Evolución del Desarrollo del Turismo en la Provincia de Entre Ríos, Argentina, Tiempo de Gestión, 5 (año IV). ISBN: 1850-7255

Wanhill, S.

2000. "Small and Medium Tourism Enterprises". Annals of Tourism Research, 27(1): 132-147. http:// dx.doi.org/10.1016/S0160-7383(99)00072-9 
World Economic Forum (WEF)

2013. The Travel \& Tourism Competitiveness. Report 2013. Reducing Barriers to Economic Growth and Job Creation. Geneva: WEF.

World Travel \& Tourism Council

2016. disponible en http://sp.wttc.org/-/media/files/reports/economic-impact-research/2016-documents/ economic-impact-summary-2016_a4-web.pdf consultado el 13 de febrero de 2017.

Zou, T., Huang, S. \& Ding, P.

2012. "Toward a Community-Driven Development Model of Rural Tourism: the Chinese Experience". International Journal of Tourism Research, 16(3), 261-271. DOI: 10.1002/jtr.1925 